\title{
Hamish Simpson, Peter Augat: Experimental research methods in orthopedics and trauma
}

\section{Thieme Verlag, New York, Stuttgart, Delhi, Rio de Janeiro, 2015, Paper Back, 480 pp, $€ 117,07$ Format Kindle: €73.84, ISBN: 978-3-13-173,111-1}

\author{
Pierre Kehr ${ }^{1}$
}

Received: 15 March 2016/Accepted: 25 April 2016/Published online: 10 June 2016

(C) Springer-Verlag France 2016

This book treats research methods experimental. The many scientific specialists stuck have to describe the state of the art of methodologies of industrial research. These methods relate to the experimental studies on the musculoskeletal apparatus.

The various chapters cover issues as different as biomechanics structural and functional, digital integrations (finite elements), the cellular and molecular studies, the techniques of imageries, the models in vivo, the tissues engineering and to finish the statistics applied has experimental research.
This book will interest not only the clinicians implied in research and requiring a methodology which could be found in this book, but also the students carrying out a diploma in research, or more simply for understanding well the literature which integrates an experimental part more and more.

Compliance with ethical standards

Conflict of interest None.

Pierre Kehr

pierre.kehr@gmail.com

1 Strasbourg, France 